\title{
Disruption of chickens' color aversions when training and test mediums are different
}

\author{
GERARD M. MARTIN \\ Memorial University, St. John's, Newfoundland, Canada
}

\begin{abstract}
In the present experiments, the conditions under which chickens would avoid colored and flavored substances that they had associated with toxicosis were examined. It was found that changing the substance from a fluid to a solid weakened color aversions more than flavor aversions. This was true despite the fact that color and flavor aversions appeared to be of equal strength and despite the fact that the birds could recognize the colors in the changed substance. Color aversions were weakened only by changes in substances at the time of test. They were not disrupted by changes in flavor or by substitution of a different container at the time of test. These data are inconsistent with conventional theories of conditioning, which would predict equal disruption of color and flavor aversions. It is suggested that birds treat color as a signal that a particular substance is dangerous and treat flavor as an aversive stimulus independent of the medium (cf. Garcia, Rusiniak, \& Brett, 1977).
\end{abstract}

Birds' success in associating color cues with induced sickness is influenced by a variety of factors. Color aversions are not as easily formed when the color is in a fluid as when it is in a solid (Gillette, Martin, \& Bellingham, 1980; Martin \& Bellingham, 1979). Many species of birds form strong color aversions only under conditions in which a taste is also present in the substance. For example, pigeons, quail, hawks, and geese do not form strong colored-water aversions unless a novel flavor is present at the time of training (Brett, Hankins, \& Garcia, 1976; Clarke, Westbrook, \& Irwin, 1979; Lett, 1980; B. T. Lett \& G. M. Martin, unpublished data). Finally color aversions do not seem to transfer readily from one medium to another (Gillette, Irwin, Thomas, \& Bellingham, 1980).

These data on birds' formation of color $\rightarrow$ sickness associations contrast with reports on rats' formation of flavor $\rightarrow$ sickness associations. Flavor aversions formed by rats can be easily demonstrated regardless of whether the flavor is presented in food or water (Bernstein, Vitiello, \& Sigmundi, 1980; Maier, Zahorik, \& Albin, 1971; Martin \& Storlien, 1976). Flavor aversions do not need special conditions for their formation since rats readily form strong taste aversions when they are passively exposed to the flavor through force feeding (Domjan, 1973) or injection (Bradley \& Mistretta, 1971). Finally, taste aversions readily transfer from one medium to another and occur in test situations other than the training

The author thanks Elizabeth Noseworthy for technical assistance and Sam Revusky and Anne Storey for reading earlier versions of this manuscript. This research was supported by Grant A7460 from the National Sciences and Engineering Council of Canada. The author's address is the Department of Psychology, Memorial University, St. John's, Nfld., Canada A1B 3X9. situation (Garcia, Kovener, \& Green, 1970; Gillette, Bellingham, \& Martin, 1979; Jones, 1980).

The sensitivity of birds' color $\rightarrow$ sickness associations and the insensitivity of rats' flavor $\rightarrow$ sickness associations to extraneous factors suggest that it might be profitable to compare color $\rightarrow$ sickness and flavor $\rightarrow$ sickness associations in birds. It is possible that taste aversions produced by sickness, as pointed out by Garcia, Rusiniak, and Brett (1977), may differ from other learned associations. In particular, it is possible that the ease with which chickens transfer colored water and flavored water aversions to solids will differ. It might be expected, for example, that colored water aversions would be affected by a change in medium to a solid, whereas flavored water aversions would not. If so, it could be argued, in agreement with Garcia et al. (1977), that birds treat color as a signal that a particular medium is dangerous and that they treat flavor as an aversive stimulus that is independent of the medium. Such an approach to external stimuli makes sense in terms of adaptation because a particular color may be used by an animal in a variety of situations other than eating and drinking. In contrast, a flavor is useful in characterizing an ingested substance and little else.

\section{General Design}

Each experiment consisted of an adaptation phase, a training phase, a recovery phase, and a testing phase. During the adaptation phase, all birds were familiarized with their new housing and with some of the substances (dry food, wet mash, tap water, or water that had the solidifying agent agar placed in it) used throughout the experiment. During the training phase, the birds were familiarized with a deprivation regimen and were trained. Training consisted 
of pairing a cue (a color or a flavor) with an injection of LiCl. During training, neophobia was controlled by exposing the birds to two novel stimuli: red and green when color was the cue, and vinegar and sodium chloride $(\mathrm{NaCl})$ when flavor was the cue. The birds were always injected with $\mathrm{LiCl}$ after exposure to the second stimulus. A recovery phase always followed the injection of $\mathrm{LiCl}$. During the recovery phase, adlib food and water were provided to the birds to ensure that they recovered from the effects of $\mathrm{LiCl}$. During the test phase, deprivation was reinitiated. The test of conditioning was a choice between two stimuli: red and green when colors were used during training, and vinegar and $\mathrm{NaCl}$ when flavors were used during training. Two-stimulus tests are more sensitive than one-stimulus tests, and they ensure that the aversions can be attributed to conditioning rather than to sensitization or the effect of poisoning on appetite (Grote \& Brown, 1971; Martin \& Timmins, 1980; Revusky \& Bedarf, 1967).

\section{Statistical Analysis}

Only test-day data are reported because the groups did not differ in food or fluid consumption prior to testing. The food-and fluid-consumption scores that were obtained during the two-stimulus tests during the test phase of each experiment were converted to preference ratios: red/(red + green) in color experiments and vinegar/(vinegar $+\mathrm{NaCl})$ in flavor experiments. Preference ratios that approached 1.0 indicated a preference for red or vinegar; preference ratios that approached 0.0 indicated a preference for green or $\mathbf{N a C l}$. Preference ratios at 0.5 indicated indifference between colors or flavors. Absolute consumption scores were also reported when they might alter the statistical decisions based on preference ratios. ANOVAs were used to analyze the data, and Newman-Keuls tests were used to make group comparisons when significant Fs were obtained.

\section{EXPERIMENT 1}

Transfer of colored water $\rightarrow$ sickness associations to colored agar by chickens was examined. Agar, rather than chicken food, was selected as the solid because the colors were minimally affected by the difference between agar and water. This assumption was initially based on the similarity, to a human observer, of colors in agar and water. The assumption was confirmed in Experiment 5 by a demonstration that chickens would treat tap water that received its color from agar as though it were colored tap water. Consequently, any difficulty chickens had transferring an aversion could be attributed to the differences in stimulus properties of tap water and agar rather than to changes in the color.

In this experiment, there was a departure from the training procedure used in subsequent experiments.
One group of birds was exposed to a solution with a novel color on the training day. Two other groups of birds were exposed to a solution that had both novel color and flavor on the training day. Combining the color and the flavor is known as the potentiation technique since the added flavor potentiates the formation of color $\rightarrow$ sickness associations in birds (Brett et al., 1976; Clarke et al., 1979; Lett, 1980). The potentiation technique has been reported to aid the transfer of colored-water aversions to colored food in domestic chickens when a single-stimulus test was employed (Gillette, Irwin, Thomas, \& Bellingham, 1980). It was hoped that the strong colored-water $\rightarrow$ sickness association produced by potentiation would aid the transfer of a colored-water aversion to agar.

\section{Method}

\section{Subjects and Apparatus}

The 33 leghorn chickens (Gallus gallus, strain Shaver 277), 30 days old at the start of the experiment, were used as the subjects. Like all other birds used in this study, these were females obtained from Newfoundland Hatchery when 1 day old. They were raised in a room, $3 \times 3 \mathrm{~m}$, that had wood shavings on the floor. Lights were on from 0600 to $2000 \mathrm{~h}$, and windows provided additional lighting.

\section{Materials}

The chickens were housed individually in wire-mesh cages $(30 \times$ $20 \times 25 \mathrm{~cm}$ high) during the experiment and were maintained on the same light-dark cycle as before the start of the experiment. Clear 400-ml plastic cups had a 4.4-cm hole placed in them $1.9 \mathrm{~cm}$ from the top. The hole permitted access to the nutrients. Food and water were placed next to each other outside the cage, and their positions were alternated each day to minimize position habits

The chickens were maintained on tap water and on Chicken Starter (starter) manufactured by Supersweet Feeds. Two additional mediums were wet mash $(100 \mathrm{~g}$ of starter in $100 \mathrm{ml}$ of tap water) and agar. Unless otherwise indicated, the agar concentration was $0.5 \%$ ( $0.5 \mathrm{~g}$ of Oxoid No. 3 agar in $100 \mathrm{ml}$ of tap water). Wet mash was always given to the chickens within $30 \mathrm{~min}$ of its preparation.

Tap water and agar were colored by adding $1 \mathrm{ml}$ of red or green Barbour's food coloring to $99 \mathrm{ml}$ of tap water. Red vinegar water $(1 \mathrm{ml}$ of red dye $+3.0 \mathrm{ml}$ of vinegar per $96 \mathrm{ml}$ of tap water) and green vinegar water $(1 \mathrm{ml}$ of green dye $+3 \mathrm{ml}$ of vinegar per $96 \mathrm{ml}$ of tap water) were also used. The food coloring was added prior to hardening the agar.

Sickness was produced during the training phase by injecting lithium chloride $(\mathrm{LiCl})$ intraperitoneally at a dosage of $212 \mathrm{mg} / \mathrm{kg}$ in a $0.5-\mathrm{M} \mathrm{LiCl}$ solution.

\section{Procedure}

Adaptation. Wet mash and $0.5 \%$ agar were provided ad lib when the chickens arrived in the laboratory. Presentation of wet mash with agar ensured that the chickens did not suffer water deprivation while becoming familiar with agar.

Training. The deprivation regimen, which consisted of two parts, was initiated on Day 6 (see Table 1). The deprivation procedure ensured that the birds were familiar with limited access to both agar and tap water. On Day 16, the chickens were assigned to one of three equally sized groups. Tap water was replaced with green vinegar water (Group 1), green water (Group 2), or red water (Group 3) during the drinking session at $1430 \mathrm{~h}$, and the amount of fluid consumed was measured. Measures of the amounts of food and fluid consumed were taken throughout all experiments 
Table 1

Deprivation Regime Employed During the Training and Test Phases of Experiment 1

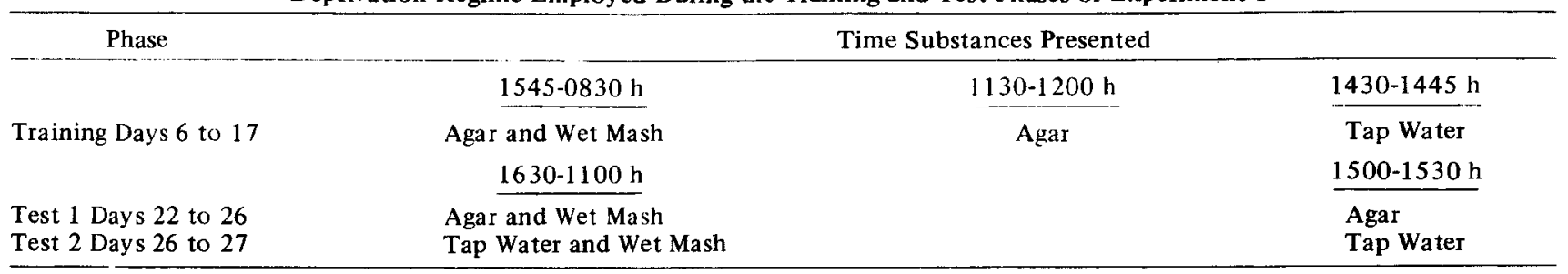

Note-Animals were provided with ad-lib food and water on all unspecified days.

by weighing the food or fluid containers prior to presentation and after removal. On Day 17, tap water was replaced with red water (Group 1), red vinegar water (Group 2), or green vinegar water (Group 3) during the session at $1430 \mathrm{~h}$. Each chicken was injected with $\mathrm{LiCl}$ immediately after the solution was removed.

Recovery. Wet mash and tap water were returned to the chickens $2 \mathrm{~h}$ after the injections. Because the first test was to be carried out with agar, agar was substituted for tap water on Day 21.

Testing. The deprivation procedure for the test phase of the experiment is summarized in Table 1 . Only one limited-access period was used, since the birds had been familiarized with limited access during the training phase. Two cups were used during the session at $1500 \mathrm{~h}$ in order to determine position preferences. The test for transfer of the colored water aversion was taken on Day 26; red and green agar were substituted for plain agar during the session at $1500 \mathrm{~h}$. The stimulus that had been paired with sickness was placed on the preferred side in all experiments. The test for the colored-water aversion was taken on Day 27; red and green water were provided during the session at $1500 \mathrm{~h}$.

\section{Results and Discussion}

Figure 1 shows the mean red-preference ratios for colored agar and colored water. A $3 \times 2$ ANOVA (groups $\times$ test days) revealed a groups $\times$ test days interaction $[F(2,30)=3.71, p<.05]$. Newman-Keuls tests on the simple main effects showed that the redtrained groups' preference for red vs. green did not differ from the preference shown by the green-trained group when the test medium was agar, a medium dif-

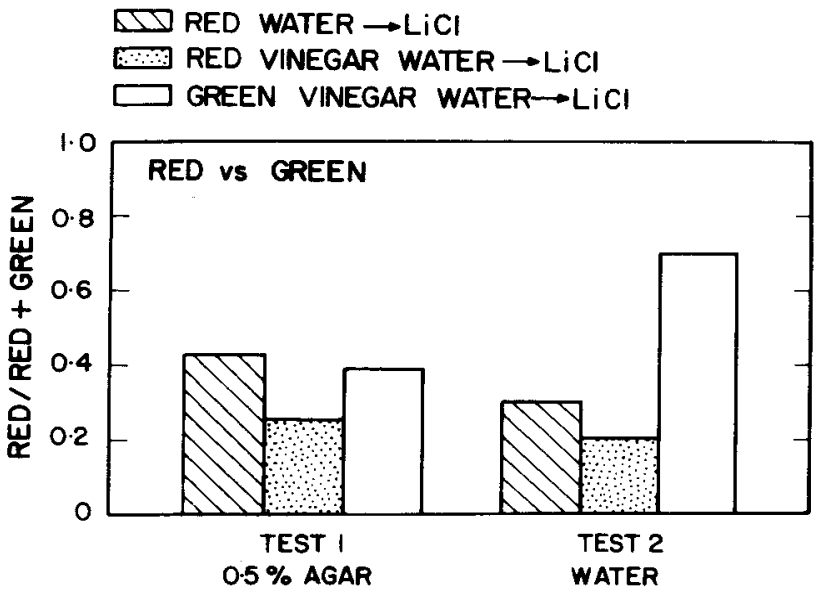

Figure 1. Mean red-preference ratios on Test Days 1 and 2 of birds that had red water, red vinegar water, or green vinegar water paired with an injection of LICl during training in Experiment 1. ferent from the training medium. The red-trained groups' red preferences were reliably lower than the red preferences of the green-trained group when the test medium was tap water, the medium used during training (ps $<.01)$. The two red-trained groups did not differ (ps $>.10)$ during Test 1 or Test 2 . The absence of a difference in color preferences between the red- and green-trained groups during the agar test and the presence of one during the water test indicates that the chickens formed a colored-water aversion that did not transfer to agar.

Absence of a difference between the red- and redvinegar-trained birds is not surprising. Two-choice tests are so sensitive that they result in floor effects that can mask differences in the strength of aversions (Martin \& Timmins, 1980). Consequently, chickens with weak aversions to red water would not have differed from chickens with strong aversions to red flavored water, since both groups would have selected green in preference to red water. Support for this suggestion can be found in Lett and Martin's unpublished data, which show that chickens, like other birds, show potentiated colored-water aversions when a single-stimulus test is used, and in the data of Experiment 4, which show that colored-water aversions are very strong when a two-stimulus test is used. These findings confirm those of Gillette et al. (1980) in that chickens do not readily transfer color aversions. Gillette et al. (1980) did succeed in obtaining transfer of a color aversion when it was conditioned by the potentiation procedure. In contrast, I failed to obtain this result. This difference might be attributed to my use of a two-stimulus test and to their use of a one-stimulus test. A two-stimulus test minimizes the importance of sensitization during testing, since the important measure is the consumption of the substance paired with sickness relative to the consumption of the substance not paired with sickness. A one-stimulus test can be affected more by sensitization since an animal's refusal to consume a particular food can reflect an aversion to a wide range of novel substances rather than an aversion to the specific substance paired with sickness. Consequently, the lower consumption in the experimental group of Gillette et al. (1980) might reflect an aversion to novel colors rather than an aversion to the specific color paired with sickness. 


\section{EXPERIMENT 2}

Experiment 2 was a counterbalanced version of Experiment 1 and was performed to determine whether chickens would have difficulty transferring coloredagar $\rightarrow \mathrm{LiCl}$ associations to colored water. Disruption of colored-agar $\rightarrow \mathrm{LiCl}$ associations when the medium was changed would indicate that the effect observed in Experiment 1 was not limited to colored-water $\rightarrow$ $\mathrm{LiCl}$ associations.

\section{Method}

\section{Subjects and Apparatus}

The subjects were 48 chickens, 40 days old at the start of the experiment. All materials were as described for Experiment 1.

\section{Procedure}

Adaptation. Chickens were kept on ad-lib starter and tap water during their first $\mathbf{4}$ days in the laboratory.

Training. On Day 5, the chickens were switched to wet mash and agar and to a deprivation regimen, which entailed a schedule for the removal and return of substances that was adhered to in all subsequent experiments. Wet mash and agar were removed at $1700 \mathrm{~h}$ and agar was returned $16 \mathrm{~h}$ later at $0900 \mathrm{~h}$ for $30 \mathrm{~min}$. Wet mash was not present during the 30 -min exposure to agar. Only one substance (food, water, or agar) was ever presented during the session at $0900 \mathrm{~h}$, and all experimental manipulations and tests were carried out during this 30 -min session. Wet mash and agar were returned $60 \mathrm{~min}$ after the 30-min exposure to agar.

On Day 14, the day prior to conditioning, 24 chickens had red agar and another 24 had green agar substituted for plain agar. On Day 15, the chickens were conditioned. Each chicken was given the colored agar that it had not received on the previous day and was injected with $\mathrm{LiCl}$ immediately after agar removal.

Recovery. One hour after the $\mathrm{LiCl}$ injection, the chickens were allowed ad-lib starter and tap water to facilitate recovery from the effects of the $\mathrm{LiCl}$. Wet mash and agar were substituted for starter and tap water on Day 18.

Testing. On Day 19 at $1700 \mathrm{~h}$, the standard deprivation procedure began. Wet mash and agar were removed. Half the redand half the green-trained birds were given agar, and the remaining birds were given tap water during each session at $0900 \mathrm{~h}$. Wet mash and agar were returned $60 \mathrm{~min}$ later. The test for the color aversion was carried out Day 25 . The birds that were receiving agar were given a choice between red and green agar. The birds that were receiving tap water were given a choice between red and green tap water.

\section{Results and Discussion}

As in Experiment 1, the color aversion was specific to the medium used during training. A $2 \times 2$ ANOVA (training color $\times$ test medium) revealed a significant interaction $[F(1,44)=5.35, p<.05]$. Newman-Keuls tests on the simple main effects showed that when the test medium was agar, the group trained on red agar $(\bar{X}=.17)$ had reliably lower red-preference ratios $(p<.01)$ than the group trained on green agar $(\bar{X}=$ .81). In contrast, when the test colors were in tap water, a medium different from the agar used in training, the group trained on red agar $(\bar{X}=.41)$ did not have a reliably lower red-preference ratio $(p>.10)$ than the group trained on green agar $(\bar{X}=.66)$. These findings indicate that the difficulty chickens have in transferring color aversions to another medium is not limited to color aversions formed when the color was in water. Thus, in both Experiments 1 and 2, color aversions were found to be specific to the training medium.

\section{EXPERIMENT 3}

Transfer of flavored water aversions to wet mash and to two concentrations of agar was examined. Transfer of taste aversions to mediums that differed from the training medium would indicate that chickens, like rats, form a taste aversion that, in contrast to color aversions, is not specific to a particular medium (Gillette et al., 1979). Moreover, successful transfer of flavor aversions would indicate that changes in medium do not disrupt all $\mathrm{LiCl}$-based aversions that are formed by chickens.

All birds had flavored-water consumption paired with an injection of $\mathrm{LiCl}$. The birds were first tested on flavored wet mash and then tested on flavored water. The flavored-water test was followed by a test on flavored $0.5 \%$ agar for one group and flavored $1.0 \%$ agar for a second group. The $1.0 \%$ agar was so solid that it had to be shredded before the chickens could eat it. Hence, the test with $1.0 \%$ agar provided a strong measure of birds' sensitivity to a change in medium when flavor aversions were involved.

\section{Method}

\section{Subjects}

Forty chickens that were $\mathbf{4 0}$ days old at the start of the experiment were used as subjects.

\section{Apparatus}

Tap water was flavored with either $3.0 \%$ vinegar $(3 \mathrm{ml}$ of Heinz Pure White Vinegar in $97 \mathrm{ml}$ of tap water) or $1.0 \% \mathrm{NaCl}(1 \mathrm{~g}$ of $\mathrm{NaCl}$ in $100 \mathrm{ml}$ of tap water). Wet mash was flavored with $35.0 \%$ vinegar (70 ml of vinegar in $30 \mathrm{ml}$ of water in $100 \mathrm{~g}$ of food), $14.0 \% \mathrm{NaCl}(28 \mathrm{~g}$ of $\mathrm{NaCl}$ in $100 \mathrm{ml}$ of water and $100 \mathrm{~g}$ of food), or $16.0 \% \mathrm{NaCl}(32 \mathrm{~g}$ of $\mathrm{NaCl}$ in $100 \mathrm{ml}$ of water and $100 \mathrm{~g}$ of food). The $0.5 \%$ agar was flavored with $12.0 \%$ vinegar $(12 \mathrm{ml}$ of vinegar in $88 \mathrm{ml}$ of tap water) or $2.0 \% \mathrm{NaCl}(2 \mathrm{~g}$ of $\mathrm{NaCl}$ in $100 \mathrm{ml}$ of tap water). The $1.0 \%$ agar was flavored with $9.0 \%$ vinegar $(9 \mathrm{ml}$ of vinegar per $91 \mathrm{ml}$ of tap water) or $3.0 \% \mathrm{NaCl}(3 \mathrm{~g}$ of $\mathrm{NaCl}$ per $100 \mathrm{ml}$ of water). The concentrations of vinegar and $\mathrm{NaCl}$ were increased when placed in agar because lower concentrations did not taste as strong to the investigator. Furthermore, high concentrations of vinear and $\mathrm{NaCl}$ were placed in wet mash, since other data collected by us had indicated that lower concentrations are not perceived by chickens, as evidenced by their failure to associate the flavors with $\mathrm{LiCl}$-induced sickness (Gillette et al., 1980; Lett \& Martin, unpublished data). The variations in concentrations of vinegar and $\mathrm{NaCl}$ represent an additional attempt to maximize the similarity of flavors between flavored water, flavored agar, and flavored wet mash. The $1.0 \%$ agar was shredded after it had hardened.

\section{Procedure}

Adaptation. Access to starter and tap water was provided ad lib during the birds' first 7 days in wire cages.

Training. On Day 8, at $1700 \mathrm{~h}$, a tap-water-deprivation regimen was initiated. On Day 11 , during the drinking session at $0900 \mathrm{~h}$, 
vinegar water was substituted for tap water for 20 birds and $\mathrm{NaCl}$ water was substituted for tap water for the remaining 20 birds. On Day 12, during the drinking session at $0900 \mathrm{~h}$, each bird was given the flavored water not experienced on the previous day and was injected with $\mathrm{LiCl}$ immediately after the fluid was removed.

Recovery. Two hours after the $\mathrm{LiCl}$ injection, the chickens were placed on ad-lib starter and tap water.

Testing. Wet mash was substituted for starter on Day 16, and a deprivation procedure was initiated. The chickens were deprived of wet mash at $1700 \mathrm{~h}$ when wet mash was to be presented at $0900 \mathrm{~h}$ on the next day. Tap water was removed at $1700 \mathrm{~h}$ when tap water was to be returned at $0900 \mathrm{~h}$ on the next day. Two groups, each of which contained 10 vinegar- and $10 \mathrm{NaCl}$-trained birds, were formed. Group 1 was given a choice between $35.0 \%$ vinegar and $14.0 \% \mathrm{NaCl}$ wet mash on Day 20 and a choice between $3.0 \%$ vinegar water and $1.0 \% \mathrm{NaCl}$ water on Day 21 . Group 2 was given a choice between $35.0 \%$ vinegar and $16.0 \% \mathrm{NaCl}$ wet mash on Day 22 and $3.0 \%$ vinegar and $1.0 \% \mathrm{NaCl}$ water on Day 23.

All birds were switched to ad-lib agar and wet mash after the flavored-water test on Group 2. Group 1 was given $0.5 \%$ agar. Group 2 was given $1.0 \%$ agar. This period of ad-lib access allowed the birds to become familiar with agar. On Day 30, the chickens were placed on a deprivation regimen. Both the agar and wet mash were removed at $1700 \mathrm{~h}$; agar was returned during the session at $0900 \mathrm{~h}$, and both substances were returned $1 \mathrm{~h}$ later. On Day 34, flavored agar was substituted for plain agar during the session at $0900 \mathrm{~h}$. Group 1 was given a choice between $12.0 \%$ vinegar and $2.0 \% \mathrm{NaCl}$ in $0.5 \%$ agar. Group 2 was given a choice between $9.0 \%$ vinegar and $3.0 \% \mathrm{NaCl}$ in $1.0 \%$ agar.

\section{Results and Discussion}

The test results for flavor aversions are presented in Figure 2. A $2 \times 3$ (training flavor $\times$ test day) ANOVA of the vinegar-preference ratios of Group 1 revealed a significant training flavor $\times$ test day interaction $[F(2,36)=7.48, p<.01]$. Newman-Keuls analyses of the simple main effects showed that the vinegar-trained group differed from the $\mathrm{NaCl}$-trained group when the test mediums were tap water or agar (ps $<.01$ ) but did not differ when the test medium was wet mash $(p>.10)$. A $2 \times 3$ (training flavor $x$ test day) ANOVA of Group 2's vinegar-preference ratios revealed the same pattern. There was a significant training flavor $\times$ test day interaction $[F(2,36)$ $=12.51, \mathrm{p}<.01]$. Newman-Keuls analyses of the simple main effects showed that the groups did not differ when the test medium was wet mash $(p>.10)$ but did differ when the test medium was tap water or $1.0 \%$ agar (ps $<.01$ ).

Transfer of flavored-water aversions to flavored agar indicates that a change in medium does not disrupt all LiCl-based aversions. Transfer of flavoredwater aversions also supports the hypothesis that chickens, like rats, form an aversion to the particular flavor that has been paired with sickness. Failure of the chickens to transfer the flavor aversion to wet mash may seem to contradict this hypothesis. I believe, however, that this failure is due to the difficulty chickens have in identifying the flavors in wet mash. The flavor of the mash interacts with the flavor of the vinegar and $\mathrm{NaCl}$ and produces flavors that are not good mimics of the vinegar and $\mathrm{NaCl}$ in water.
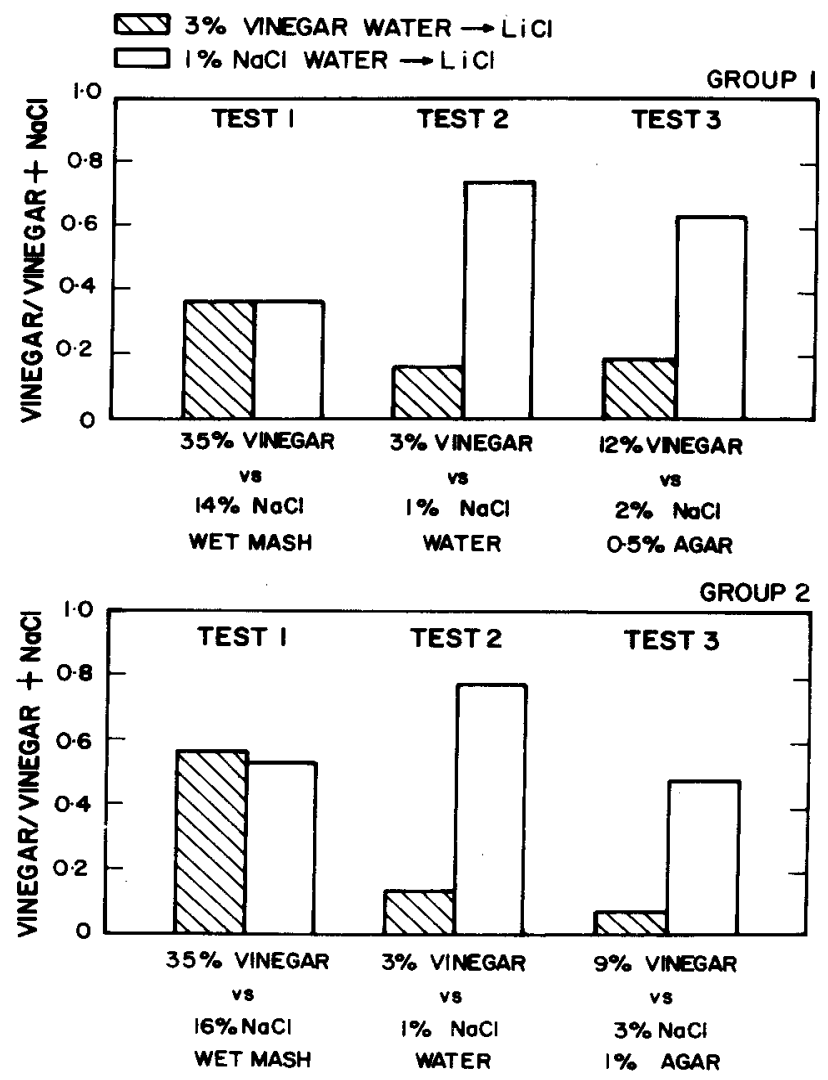

Figure 2. Mean vinegar preference ratios on Test Days 1, 2, and 3 of birds that had vinegar water or $\mathrm{NaCl}$ water paired with an injection of LiCl during training in Experiment 3.

This interaction probably prevents the chickens from distinguishing the vinegar-flavored mash from the $\mathrm{NaCl}$-flavored mash. It is unlikely that performance of chickens on flavored wet mash can be improved. Absolute consumption scores indicate that chickens notice the flavors but do not identify them as the flavors that have been used during training. Alternatively, the postingestional effects of the flavored foods suppress the chickens' food consumption. Group 1, for example, ate $(\bar{X}=21.70 \mathrm{~g})$ less flavored wet mash than the unflavored wet mash consumed by Group $2(\bar{X}=42.82 \mathrm{~g})$ on Day 20 . Group $2(\bar{X}=$ $21.55 \mathrm{~g}$ ) ate less flavored mash than the unflavored mash that was consumed by Group $1(\bar{X}=46.83 \mathrm{~g})$ on Day 22. A similar finding was obtained with chickens when flavored wet mash was paired with LiCl-induced sickness (Gillette et al., 1980). The flavoring in the mash reduced the chickens' consumption, but the chickens did not form aversions to the flavors.

\section{EXPERIMENT 4}

Arguably, colored-water $\rightarrow$ sickness associations do not transfer to new media as readily as flavored- 
water $\rightarrow$ sickness associations because colored-water aversions are weaker than flavored-water aversions. If this is so, the difference in transferability of color and taste aversions does not indicate a basic difference in the animals' treatment of colors and flavors. Experiment 4 evaluated this possibility. Chickens were trained on either colored or flavored water, and the relative strength of the color and flavor aversions were compared over three extinction trials.

\section{Method}

\section{Subjects and Apparatus}

The $\mathbf{4 0}$ chickens used as subjects were $\mathbf{4 0}$ days old. All materials were as described earlier.

\section{Procedure}

Adaptation. The chickens were maintained on ad-lib starter and tap water during the first 7 days in the laboiatory.

Training. Tap-water deprivation began on Day 8 at $1700 \mathrm{~h}$. On Day 10, during the drinking session at $0900 \mathrm{~h}, 10$ birds had red, 10 had green, 10 had vinegar, and 10 had $\mathrm{NaCl}$ water substituted for tap water. On Day 11, during the drinking session at $0900 \mathrm{~h}$, the birds were given the color or flavor not experienced on the previous day. Removal of the colored or flavored water was followed by an injection of $\mathrm{LiCl}$.

Recovery. The chickens were placed on ad-lib tap water and starter $2 \mathrm{~h}$ after the injections.

Testing. Tap-water deprivation was reinitiated on Day 15 at $1700 \mathrm{~h}$. Tests were carried out on Days 17,18 , and 19 during the session at $0900 \mathrm{~h}$. Birds trained on a flavor were given a choice between $3.0 \%$ vinegar and $1.0 \% \mathrm{NaCl}$-flavored tap water. Birds trained on a color were given a choice between red and green tap water. The position of the test solutions was reversed each test day.

\section{Results and Discussion}

The aversions shown to colored and flavored water were comparable over 3 test days. A $2 \times 2 \times 3$ (modality of cue $\times$ training cue $\times$ test days) ANOVA showed that the groups differed as a function of training cue $[F(1,36)=204.9, p<.01]$. No other differences were found. As can be seen in Figure 3, the trainingcue effect reflects the aversions shown by the animals to the solutions upon which they were trained. Additional tests may have revealed a difference between the magnitude of the color and taste aversions. I believe, however, that the lack of a difference after three extinction trials provides sufficient proof that color and taste aversions were of similar strength when a two-stimulus test was used. The strength of the colored-water aversion when a two-stimulus test was used contrasts with the weak colored-water aversions that are observed when a single-stimulus test is used (Gillette et al., 1980; Lett \& Martin, unpublished data). Apparently, the colored-water aversion formed by chickens is influenced by the presence of a choice at the time of test.

These data indicate that one cannot readily attribute the difficulty chickens have in transferring color aversions to a weak colored-water $\rightarrow$ sickness asso-
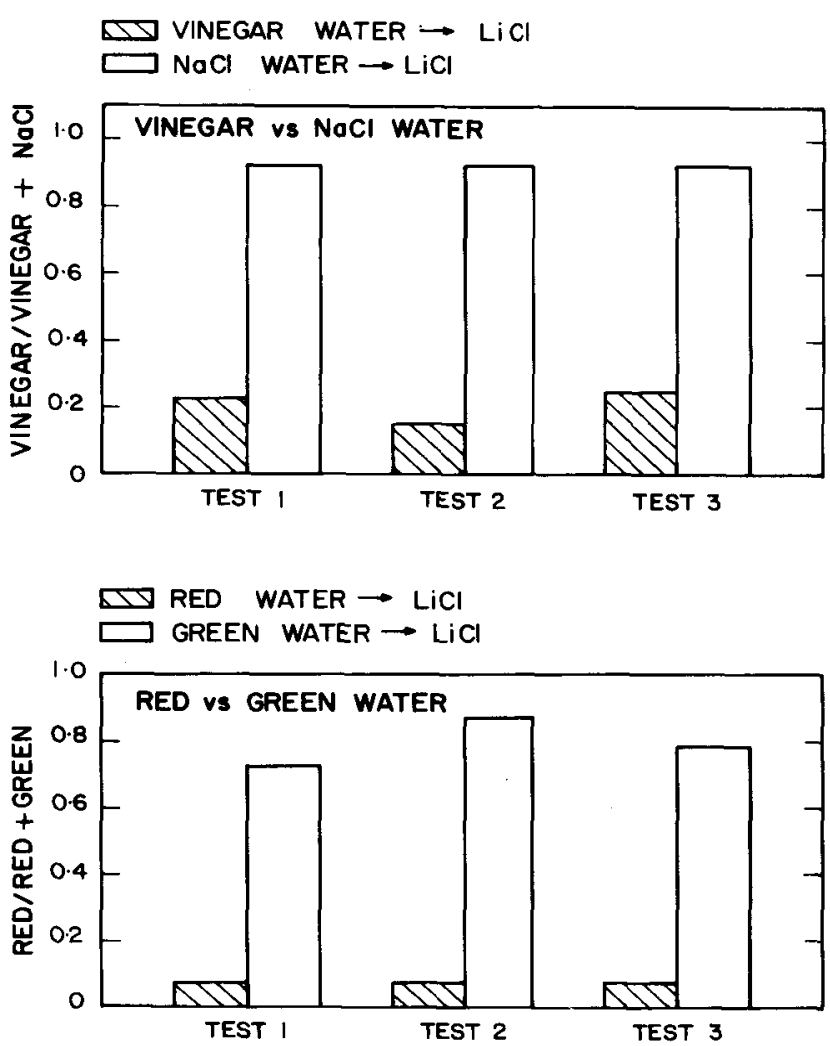

Figure 3. Mean vinegar- and red-preference ratios on Test Days 1,2 , and 3 of birds that had either flavored water (vinegar or $\mathrm{NaCl}$ ) or colored water (red or green) paired with an injection of $\mathrm{LiCl}$ during training in Experiment 4.

ciation. The failure of chickens to transfer coloredwater $\rightarrow$ sickness associations must reflect some property of the association other than its strength.

\section{EXPERIMENT 5}

Experiment 5 was concerned with whether an inadvertent change in flavor, when the medium was changed, had disrupted color aversions in earlier experiments. An important role for flavor changes would be surprising, since presentation of a novel flavor at the time of training, but not at test, does not disrupt color aversions but actually potentiates them (Brett et al., 1976; Clarke et al., 1979; Lett, 1980). It is possible, however, that the effect of flavors on birds' color aversions is asymmetrical. Hence, novel flavors at the time of test may disrupt color aversions. This possibility was assessed through a deliberate change in the flavor of colored water at the time of test.

A second test determined whether changing the medium also changed the color. Accidental changes in color could explain the disruptive effect of changes in medium on color aversions. It was important that this possibility be tested, since an interaction between 
flavors and wet mash prevented transfer of flavoredwater aversions to wet mash. Similarly, a peculiar interaction between the color and agar or the color and tap water could also cause color-aversion disruptions when the medium was changed. Chickens were given the opportunity to drink tap water from a cup that had a red or green agar color because it had been placed in a cup that had contained colored agar. The tap water placed in the second cup took on the color of agar without taking on its texture or flavor. An aversion to tap water in agar-colored cups would indicate that chickens identify the colors, red and green, in the changed medium.

\section{Method}

\section{Subjects}

Forty-eight chickens, $\mathbf{4 0}$ days old, were used.

\begin{abstract}
Apparatus
Flavored red and green vinegar used during testing consisted of $1 \mathrm{ml}$ of colored dye, $3 \mathrm{ml}$ of vinegar, and $96 \mathrm{ml}$ of tap water. Agar-colored cups were used during the second test. They were made by pouring colored agar prior to hardening into clear plastic cups as described for Experiment 1. A second cup, similar to the first cup except that the hole in its side was $2.6 \mathrm{~cm}$ from the top, was inserted into the first cup and the agar squeezed up between the two cups. Tap water placed inside the second cup took on the color of the agar.
\end{abstract}

\section{Procedure}

Adaptation. All chickens were maintained on ad-lib starter and tap water during the first 7 days in the laboratory.

Training. On Day 7, at $1700 \mathrm{~h}$, a tap-water-deprivation regimen was initiated. On Day 10, during the drinking session at $0900 \mathrm{~h}$, green water was substituted for tap water for 24 birds, and red water was substituted for tap water for the remaining birds. On Day 11, during the session at $0900 \mathrm{~h}$, the birds were given the colored solution they had not received on the previous day and were injected with $\mathrm{LiCl}$ immediately after fluid removal.

Recovery. Two hours after the $\mathrm{LiCl}$ injection, the chickens were placed on ad-lib starter and tap water.

Testing. Tap-water deprivation was reintroduced on Day 15 at $1700 \mathrm{~h}$. Half the red- and green-trained birds were given a choice between red-vinegar and green-vinegar water on Day 18 . The remaining red-and green-trained birds were given a choice between red and green tap water.

Both starter and tap water were removed on Day 18 at $1700 \mathrm{~h}$. The second test was carried out on Day 19. The birds that had been tested on colored water that was flavored were given tap water in red- and green-agar-colored cups. Birds that had been tested on colored tap water were given a choice between red and green $0.5 \%$ agar.

\section{Results and Discussion}

The top of Figure 4 shows the preference ratios for the first test when the birds were given colored water or colored water that also contained a flavor. A $2 \times 2$ ANOVA (training color $\times$ test condition) revealed that there was an effect of training color $[F(1,44)=78.22, p<.01]$. All other effects were not significant $(\mathrm{ps}>.10)$. These findings indicate that it is not a change in the flavor of the test medium that produces the disruption of color aversions. This
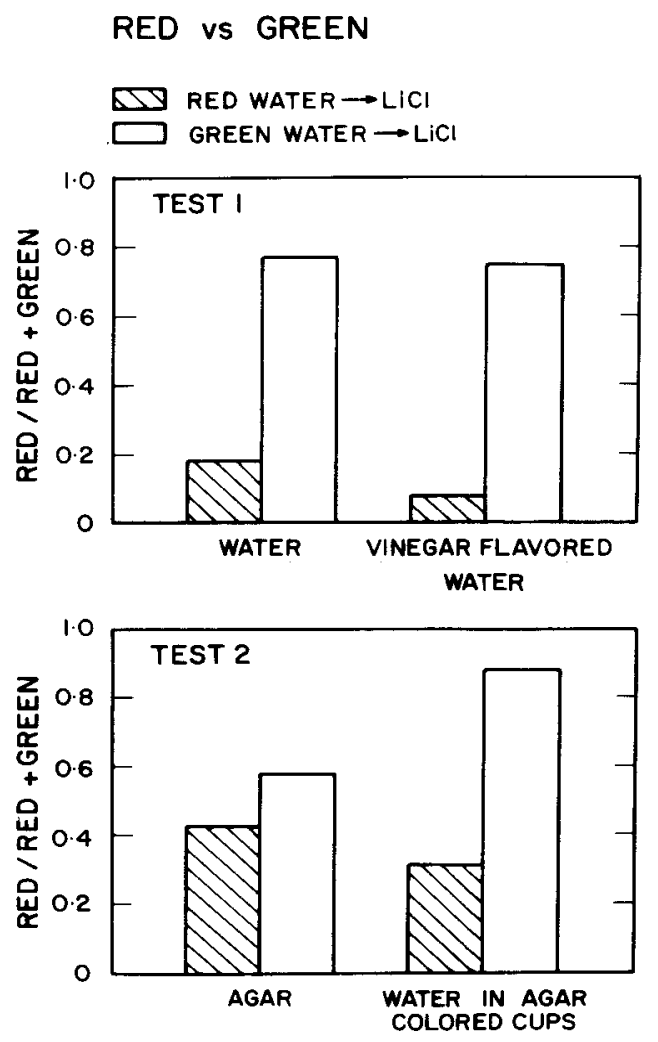

Figure 4. Mean red-preference ratios on Test Days 1 and 2 of birds that had either red or green water paired with an injection of $\mathrm{LiCl}$ during training in Experiment 5.

finding cannot be attributed easily to the unimportance of flavor. As evidenced by the ease with which they formed a flavored-water aversion in Experiment 3, chickens do notice the flavor.

The bottom of Figure 4 shows the preference ratios for the second test when the birds were given colored agar or tap water in agar-colored cups. A $2 \times 2$ ANOVA (training color $\times$ test condition) revealed a training color $\times$ test condition interaction $[F(1,44)$ $=9.96, \mathrm{p}<.01]$. Newman-Keuls tests of the simple main effects showed that groups tested on colored agar did not differ $(p>.10)$ and that groups tested on tap water in agar-colored cups did differ $(p<.01)$. Transfer of colored-water aversions to water in agarcolored cups indicates that the chickens could recognize the colors red and green as similar when in either agar or tap water. It appears, then, that it is not a shift in color that disrupts chickens' color aversion when the medium is changed.

\section{EXPERIMENT 6}

Disruption of color aversions by a change in medium could reflect the sensitivity of chickens to any alteration in the semblance of the test situation. This hypothesis was tested by substituting tubes and white 
cups during colored-water tests for the clear cups that had been used during training. The new containers changed the appearance of the test situation. Hence, the importance of constancy in the appearance of the situation could be assessed.

\section{Method}

\section{Subjects}

The subjects were 36 chickens that were 40 days old at the start of the experiment.

\section{Apparatus}

In addition to clear cups, two other types of container were used. One was a glass tube, with a diameter of $3.5 \mathrm{~cm}$ and a length of $18 \mathrm{~cm}$, that was attached to the front of a cage with clips. Each tube had a drinking spout that had an outside diameter of $2.0 \mathrm{~cm}$ and a depth of $3.0 \mathrm{~cm}$. The other type of container was a white cup that differed from the clear cups only in color and transparency.

\section{Procedure}

Adaptation. The chickens were given ad-lib access to starter and tap water in clear cups during Days 1 to 3.

Training. Tap-water deprivation started on Day 4 at $1700 \mathrm{~h}$. On Day 8, half the birds were given red water and the other half were given green water instead of tap water during the drinking session at $0900 \mathrm{~h}$. On Day 9 the birds were given the colored water not experienced on the previous day and were injected with $\mathrm{LiCl}$ immediately after its removal.

Recovery. Ad-lib starter and tap water were provided $2 \mathrm{~h}$ after the injections.

Testing. On Day 13, tap-water deprivation was introduced at $1700 \mathrm{~h}$. During the session at $0900 \mathrm{~h}, 9$ red-trained and 9 greentrained birds were tested on red and green water in glass tubes; the remaining 18 birds were tested on red and green water in clear cups. On the next day, the birds that had been tested on tubes were tested on red and green water in white cups and the remaining birds were tested again on red and green water in clear cups.

\section{Results and Discussion}

Figure 5 shows the color preference ratios. A $2 \times$ $2 \times 2$ ANOVA (container varied $\times$ training color $\times$ test day) on red-preference ratios revealed that the group trained on red water had lower red-preference ratios than the group trained on green water $[F(1,32)$ $=24.78, p<.01]$. No other effects were reliable (ps $>.10)$. These findings indicate that altering the container did not affect the chickens' colored-water aversion. Hence, not all changes in visual cues at the time of test influence the color aversions of chickens.

\section{EXPERIMENT 7}

Chickens may not have noticed that the containers were changed at the time of test in the previous experiment. Such a failure would account for the demonstration of an aversion although the appearance of the test situation had been changed. This hypothesis was tested by pairing white cups, for one group, and tubes, for another group, with $\mathrm{LiCl}$-induced sickness. Successful demonstration of aversions would show that chickens notice the containers.
RED vs GREEN
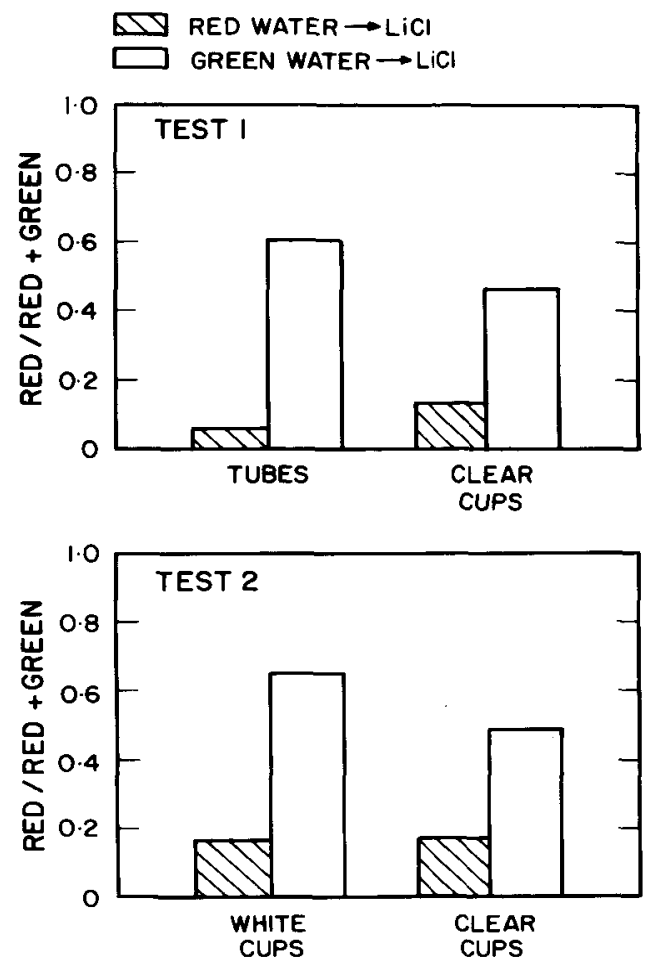

Figure 5. Mean red-preference ratios on Test Days 1 and 2 of birds that had either red or green water paired with an injection of $\mathrm{LiCl}$ during training in Experiment 6.

\section{Method}

\section{Subjects and Apparatus}

Thirty-two chickens, 40 days old, were used. All materials were as described earlier.

\section{Procedure}

Adaptation. The chickens were maintained on ad-lib starter and tap water in clear cups during the first 7 days in the laboratory.

Training. Tap-water deprivation began on Day 7 at $1700 \mathrm{~h}$. On Day 10, tap water was presented in tubes for half the chickens and in white cups for the other half during the session at $0900 \mathrm{~h}$. On Day 11, the birds that had been given tap water in tubes were given tap water in white cups and the birds that had been given water in white cups were given water in tubes. All birds were injected with $\mathrm{LiCl}$ immediately after the containers were removed.

Recovery. The chickens were put on ad-lib starter and tap water $2 \mathrm{~h}$ after the injections.

Testing. Tap-water deprivation was reintroduced on Day 15 at $1700 \mathrm{~h}$. On the test days, Days 18 and 19 , a white cup and a narrow-spouted tube of tap water were substituted for the two clear cups of tap water during the session at $0900 \mathrm{~h}$.

\section{Results and Discussion}

Examination of Figure 6 shows that chickens that had tubes paired with LiCl-induced sickness drank from white cups and that birds that had white cups paired with sickness drank from tubes. A $2 \times 2$ ANOVA (training container $\times$ test day) of the pref- 


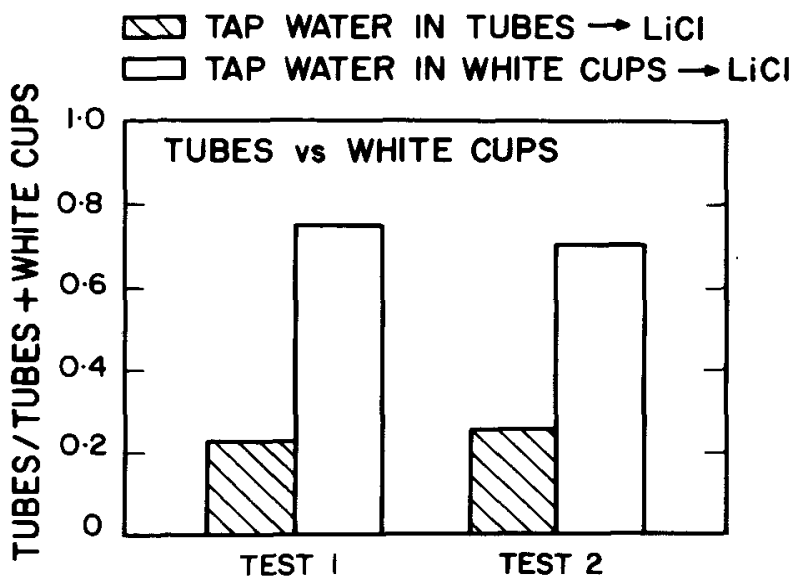

Figure 6. Mean tube-preference ratios on Test Days 1 and 2 of birds that had either tubes or white cups paired with injections of LiCl during training in Experiment 7.

erence ratios (fluid consumption from tubes/fluid consumption from tubes + fluid consumption from white cups) showed that the chickens drank less from the container that had been paired with sickness $[F(1,30)=20.1, p<.01]$. No other differences were significant.

\section{GENERAL DISCUSSION}

These findings are consistent with the distinction between flavor aversions and aversions to other stimuli that was offered by Garcia et al. (1977). Taste aversions are nearly independent of context in both mammals and birds. Color aversions, even if as strong as taste aversions, are formed in a context that is important for their retrieval. The important aspect of the context seems to be the medium, since changes in other aspects of the test situation did not disrupt color aversions. Subtle shifts in color when the medium was changed could not account for the disruption of color aversions, for the chickens recognized the colors when given tap water in agar-colored cups. The apparent importance of constancy of medium for the demonstration of good color aversions is consistent with findings that show large differences between chickens' treatment of colors in fluids and colors in solids (Gillette et al., 1980). Difficulty in transfer, then, may be another indicator that a special relationship exists with color cues in solids and fluids. That flavor aversions were not disrupted by changes in medium is consistent with data reported on rats (Garcia et al., 1977; Gillette et al., 1979; Jones, 1980). It is possible, however, that some shift in environmental cues would influence the transfer of flavor aversions. It is hard to guess what that shift might be, since the available data from rats indicate that manipulation of environmental cues does not disrupt flavor aversions that have been formed.
That the role of background cues is different for different target cues (color and taste) is a problem for conventional theories of conditioning and discrimination learning. These theories assume that background cues, the medium in the previous experiments, acquire a fixed associative value during conditioning (e.g., Rescorla \& Wagner, 1972) or that the amount of transfer between training and test is a function of the similarity of the two situations (e.g., Medin, 1975). In other words, the importance of background cues should be equal when different target cues are used if the target cues are of equal salience. Hence, animals should show complete recall of the target cue when the background cues are changed if the target cue completely overshadows the background cues. Moreover, any deficits in recall of the target cue when the background cues are changed would reflect the associative strength of the background cues relative to the target cue. In these experiments it appeared that the color and flavor cues, the target cues, had equivalent associative strength, since colored- and flavored-water aversions were of equal strength. It could expected, then, that changes in medium would cause equal disruption of the color and flavor aversions. This did not happen. When the background cues are changed the aversion to the flavor is evident but the aversion to the color is not. It appears that the relationship between target cues and background cues can vary and that the interaction between target and background cues influences whether or not an association will be retrieved when the test and training situations differ.

Only three aspects of the appearance of the medium were controlled by placing tap water in agarcolored cups. These were wavelength, purity, and reflectance, whose psychophysical correlates are, respectively, hue, saturation, and brightness (Padgham \& Saunders, 1975). Other features that do not have psychophysical correlates along the dimension of color, such as finish, surface texture, and transparency of different colored mediums, were not controlled. These factors have been found to influence the perception of color by humans, although the mechanism by which the effect is produced is unspecified (Katz, 1935; Merleau-Ponty, 1962; Padgham \& Saunders, 1975). It is possible, then, that some interaction between these factors and color, but not taste, causes the disruption of color, but not taste, aversions when the medium is changed.

\section{REFERENCES}

Bernstein, I., Vitiello, M., \& Sigmundi, R. (1980). Effects of interference stimuli on the acquisition of learned aversions to food in the rat. Journal of Comparative and Physiological Psychology, 94, 921-931.

Bradley, R. M., \& Mistretta, C. M. (1971). Intravascular taste in rats as demonstrated by conditioned aversion to sodium saccharin. Journal of Comparative and Physiological Psychology, 75, 186-189. 
Brett, L. P., Hankins, W. G., \& Garcia, J. (1976.) Preylithium aversions III: Buteo hawks. Behavioral Biology, 17, $87-98$.

Clarke, J., Westbrook, R., \& Irwin, J. (1979). Potentiation instead of overshadowing in the pigeon. Behavioral and Neural Biology, 25, 18-29.

DomJan, M. (1973). Role of ingestion in odor-toxicosis learning in the rat. Journal of Comparative and Physiological Psychology, 84, 507-521.

Garcia, J., Kovener, R., \& Green, K. (1970). Cue properties vs. palatability of flavors in avoidance learning. Psychonomic Science, 20, 313-314.

Garcia, J., Rusiniak, K., \& Brett, L. P. (1977). Conditioning food-illness aversions in wild animals: Caveant canonici. In H. Davis \& H. Hurwitz (Eds.), Operant-Pavlovian interactions. Hillsdale, NJ: Erlbaum.

Gillette, K., Bellingham, W. P., \& Martin, G. M. (1979) Transfer of a taste aversion from food to water under various states of deprivation. Animal Learning \& Behavior, 7, 441-446.

Gillette, K., Irwin, J., Thomas, D., \& Bellingham, W. P. (1980). Transfer of coloured food and water aversions in domestic chicks. Bird Behaviour, 2, 37-47.

Gillette, K., Martin, G. M., \& Bellingham, W. (1980). Differential use of food and water cues in the formation of conditioned aversions by domestic chicks (Gallus gallus). Journal of Experimental Psychology: Animal Behavior Processes, 6, 99-111.

Grote, F., \& Brown, R. (1971). Conditioned taste aversions: Two-stimulus tests are more sensitive than one-stimulus tests. Behavior Research Methods \& Instrumentation, 3, 311-312.

JoNEs, L. (1980). Taste aversion conditioning and T-maze behaviour. Australian Journal of Psychology, 32, 95-110.

KAtz, D. (1935). The world of colour. London: Kegan Paul, Trench, Trubner.
LETT, B. T. (1980). Taste potentiates color-sickness associations in pigeons and quail. Animal Learning \& Behavior, 8, 193-198. Maien, S. F., Zahonik, D. M., \& Albin, R. W. (1971). Relative novelty of solid and liquid diet during thiamine deficiency determines development of thiamine-specific hunger. Journal of Comparative and Physiological Psychology, 74, 254-262.

Martin, G. M., \& Bellingham, W. P. (1979). Learning of visual food aversions by chickens (Gallus gallus) over long delays. Behavioral Biology, 25, 58-68.

Martin, G. M., \& Storlien, L. H. (1976). Anorexia and conditioned taste aversions in the rat. Learning and Motivation, 7, 274-282.

Martin, G. M., \& Timmins, W. K. (1980). Taste-sickness associations in young rats over varying delay, stimulus, and test conditions. Animal Learning \& Behavior, 8, 529-533.

Medin, D. L. (1975). A theory of context in discrimination learning. In G. H. Bower (Ed.), Psychology of learning and motivation: Advances in research and theory (Vol. 9). New York: Academic Press.

Merlenu-Ponty, M. (1962). Phenomenology of perception. London: Routledge \& Kegan Paul.

Padgham, C. A., \& Saunders, J. E. (1975). The perception of light and colour. New York: Academic Press.

Rescorla, R. A., \& Wagner, A. R. (1972). A theory of Pavlovian conditioning: Variations in the effectiveness of reinforcement and nonreinforcement. In A. Black \& W. F. Prokasy (Eds.), Classical conditioning II: Current research and theory. New York: Appleton-Century-Crofts.

REvusky, S., \& BeDARF, E. (1967). Association of illness with prior ingestion of novel foods. Science, 155, 219-220.

(Manuscript received March 21, 1983; revision accepted for publication August 25, 1983.) 